\title{
Operative and nonoperative adverse events in the management of traumatic fractures of the thoracolumbar spine: a systematic review
}

\author{
George M. Ghobrial, M.D., ${ }^{1}$ Christopher M. Maulucci, M.D., ${ }^{1}$ \\ Mitchell Maltenfort, Ph.D., Richard T. Dalyai, M.D., 1 \\ Alexander R. Vaccaro, M.D., Ph.D., ${ }^{2}$ Michael G. Fehlings, M.D., Ph.D., F.R.C.S.C., ${ }^{3}$ \\ John Street, M.D., Ph.D., ${ }^{4}$ Paul M. Arnold, M.D., ${ }^{5}$ and James S. Harrop, M.D. ${ }^{1}$ \\ ${ }^{1}$ Department of Neurological Surgery, Thomas Jefferson University Hospital, Philadelphia; ${ }^{2}$ Rothman \\ Institute, Philadelphia, Pennsylvania; ${ }^{3}$ University Health Network, Toronto, Ontario; ${ }^{4}$ University of British \\ Columbia, Vancouver, British Columbia, Canada; and ${ }^{5}$ University of Kansas, Kansas City, Kansas
}

Object. Thoracolumbar spine injuries are commonly encountered in patients with trauma, accounting for almost $90 \%$ of all spinal fractures. Thoracolumbar burst fractures comprise a high percentage of these traumatic fractures (45\%), and approximately half of the patients with this injury pattern are neurologically intact. However, a debate over complication rates associated with operative versus nonoperative management of various thoracolumbar fracture morphologies is ongoing, particularly concerning those patients presenting without a neurological deficit.

Methods. A MEDLINE search for pertinent literature published between 1966 and December 2013 was conducted by 2 authors (G.G. and R.D.), who used 2 broad search terms to maximize the initial pool of manuscripts for screening. These terms were "operative lumbar spine adverse events" and "nonoperative lumbar spine adverse events."

Results. In an advanced MEDLINE search of the term "operative lumbar spine adverse events" on January $8,2014,1459$ results were obtained. In a search of "nonoperative lumbar spine adverse events," 150 results were obtained. After a review of all abstracts for relevance to traumatic thoracolumbar spinal injuries, 62 abstracts were reviewed for the "operative" group and 21 abstracts were reviewed for the "nonoperative" group. A total of 14 manuscripts that met inclusion criteria for the operative group and 5 manuscripts that met criteria for the nonoperative group were included.

There were a total of 919 and 436 patients in the operative and nonoperative treatment groups, respectively. There were no statistically significant differences between the groups with respect to age, sex, and length of stay. The mean ages were 43.17 years in the operative and 34.68 years in the nonoperative groups. The majority of patients in both groups were Frankel Grade E (342 and 319 in operative and nonoperative groups, respectively). Among the studies that reported the data, the mean length of stay was 14 days in the operative group and 20.75 in the nonoperative group.

The incidence of all complications in the operative and nonoperative groups was $300(32.6 \%)$ and $21(4.8 \%)$, respectively $(\mathrm{p}=0.1065)$. There was no significant difference between the 2 groups with respect to the incidence of pulmonary, thromboembolic, cardiac, and gastrointestinal complications. However, the incidence of infections (pneumonia, urinary tract infection, wound infection, and sepsis) was significantly higher in the operative group ( $\mathrm{p}=$ 0.000875 ). The incidence of instrumentation failure and need for revision surgery was $4.35 \%$ (40 of 919 ), a significant morbidity, and an event unique to the operative category $(\mathrm{p}=0.00396)$.

Conclusions. Due to the limited number of high-quality studies, conclusions related to complication rates of operative and nonoperative management of thoracolumbar traumatic injuries cannot be definitively made. Further prospective, randomized studies of operative versus nonoperative management of thoracolumbar and lumbar spine trauma, with standardized definitions of complications and matched patient cohorts, will aid in properly defining the risk-benefit ratio of surgery for thoracolumbar spine fractures.

(http://thejns.org/doi/abs/10.3171/2014.4.FOCUS1467)

$\begin{array}{llllll}\text { KEY WoRds } & \text { lumbar spine } \quad \text { thoracic spine } & \bullet & \text { complications } & \bullet & \text { trauma } \\ \text { thoracolumbar } & \bullet \quad \text { nonoperative fracture }\end{array}$

I $\mathrm{N}$ the trauma population, thoracolumbar spine injuries are frequently encountered, accounting for almost $90 \%$ of all spinal fractures. ${ }^{18,21,27,32}$ Of these fractures, tho-

Abbreviations used in this paper: $\mathrm{LOS}=$ length of stay; VAS = visual analog scale. racolumbar burst fractures comprise a significantly high percentage (45\%). Fortunately, approximately half of the patients with this injury pattern are neurologically intact..$^{29}$ Recent multicenter, prospective cohort data suggest that early (defined as less than 24 hours) surgery of spinal fractures optimizes functional outcomes in those presenting 


\section{G. M. Ghobrial et al.}

with neurological impairment. ${ }^{22}$ However, a debate over optimal treatment with operative versus nonoperative management of various thoracolumbar fracture morphologies is ongoing. This management is of particular concern for patients presenting without a neurological deficit. Advocates of surgical intervention note that operative treatment offers superior stability during the initial phase of healing, which may result in a decreased incidence of kyphotic deformity compared with nonoperative management. Furthermore, increased mechanical stability and capitalizing on immediate neural decompression have been shown to translate into decreased pain, earlier ambulation, shorter hospital stays, and earlier return to work. ${ }^{16}$

Classification schemes have been used to aid in the management of thoracolumbar fractures, and also may serve in the future to make published surgical data more meaningful. ${ }^{38}$ Randomized trials comparing operative to nonoperative management of thoracolumbar injuries in the neurologically intact patient are limited to burst fractures, and have found no immediate advantage of operative stabilization over bracing. ${ }^{49}$

Nonoperative treatment principally involves immobilization of the affected region of the spine with an external orthosis, but also uses postural reduction, bed rest, and rehabilitation. ${ }^{16}$ Experience with nonoperative treatment of stable thoracolumbar spinal fractures with successful results is well documented. 6,8,12,17,23,33,40,41,48

There is a lack of consensus with regard to the ideal operative management of many thoracolumbar fracture patterns, because there are limited long-term data on outcomes and procedural complication rates. Therefore, a systematic review of the literature was conducted to compare the complication rates of operative and nonoperative management of these thoracolumbar burst (AO Type A3) pathological entities. Although previous systematic reviews ${ }^{16,45,47}$ have focused on functional outcomes, to our knowledge this is the only review in the literature with a primary emphasis on relative adverse event rates.

\section{Methods}

A MEDLINE search for pertinent literature published between 1966 and December 2013 was performed using 2 broad search terms to maximize the initial pool of manuscripts for screening. These terms were "operative lumbar spine adverse events" and "nonoperative lumbar spine adverse events," as well as within the Medical Subject Heading (MeSH) terminology: "postoperative complications" and "neurosurgery:surgical procedure, operative." Furthermore, articles were supplemented with known literature on the topic as well as reviews of articles in references.

\section{Inclusion Criteria}

Articles included were those already published or published online prior to print, written in English, and that involved only human subjects. Comparative case series, comparative cohort studies, clinical trials, metaanalyses, and systematic reviews were eligible for inclusion. Relevant papers were then selected by 2 of the authors (G.G. and R.D.) and articles of interest from the respective bibliographies were identified, and then all of these articles were reviewed for inclusion by the remaining authors. The articles that were included all analyzed 1 or more variables described in the pertinent question; namely operative or nonoperative intervention for a lumbar or thoracolumbar fracture, including any thoracic stabilization crossing the thoracolumbar junction as well as articles containing adverse event data. Analyses that met these criteria were included for comparison with results. These references were reviewed in detail to confirm that no individual studies were duplicated in the final analysis.

\section{Exclusion Criteria}

Papers that were excluded were laboratory or animal research studies, non-English publications, case studies, commentaries, noncomparative and descriptive studies, technical notes, and those articles deemed to be irrelevant to the study topics of interest by 2 authors (G.G. and R.D.). Relevant manuscripts that appeared in both searches were included in both groups for analysis if they were comparative studies.

\section{Treatment Outcomes}

The primary outcome of interest was the overall incidence of adverse events. Secondary outcomes were the reported rates of thromboembolic, infectious, pulmonary, cardiac, and gastrointestinal adverse events. Other secondary outcomes included the incidence of technical adverse events such as durotomy, CSF leak, new or worse neurological deficits, and instrumentation failure. Studies that met these criteria were included in the final analysis.

\section{Data Analysis}

Grading of articles on quality of evidence was done via the Oxford Center for Evidence-Based Medicine ranking criteria. ${ }^{25}$ Data extracted were confirmed by 2 authors (G.G. and R.D.) on an independent basis. A proprietary software package was used for statistical analysis ("R" version 3.0.2, the R Foundation for Statistical Computing). A generalized mixed model controlling for random effect was used. A mixed logistic regression model was used for gender comparisons as well as for age comparisons.

\section{Results}

In an advanced MEDLINE search of the term "operative lumbar spine adverse events" on January 8, 2014, 1459 results were obtained. In a search of "nonoperative lumbar spine adverse events," 150 results were obtained. After a review of all abstracts for relevance to traumatic thoracolumbar spinal injuries, 62 abstracts were reviewed for the "operative" group and 21 abstracts were reviewed in the "nonoperative" group (Fig. 1). A total of 14 manuscripts met inclusion criteria for the operative group and 5 manuscripts met criteria for the nonoperative group, and were included (Table 1).

There were a total of 919 and 436 patients in the operative and nonoperative treatment groups, respectively (Table 2). There were no statistically significant differences between the groups with respect to age, sex, and 


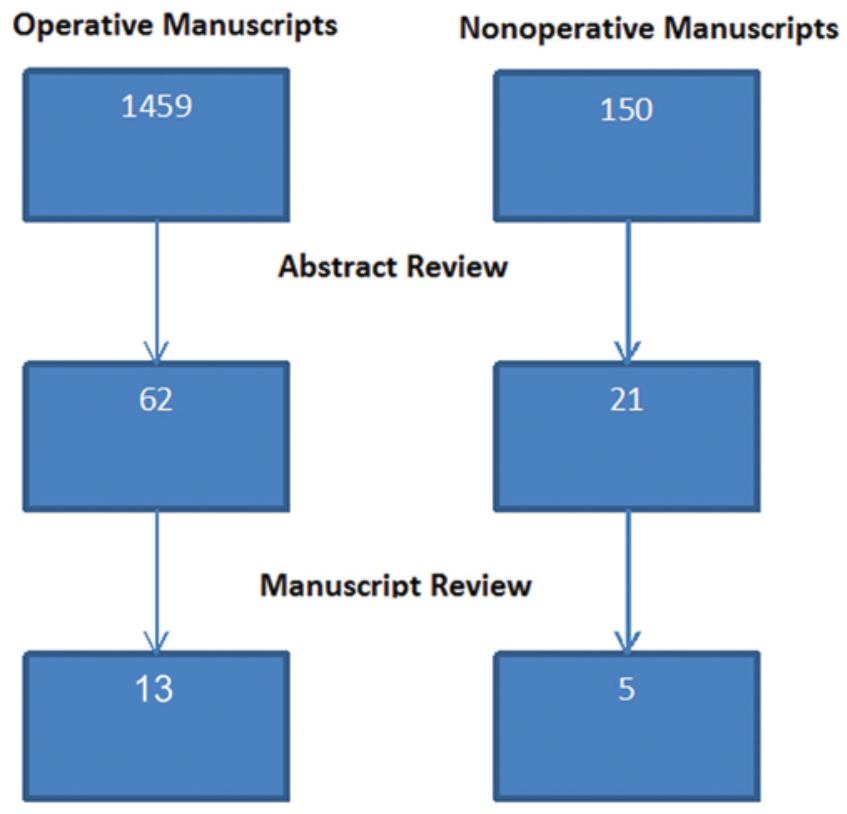

FIG. 1. Flow chart showing manuscript review process.

length of stay (LOS). The mean ages were 43.2 years in the operative and 34.7 years in the nonoperative groups. The majority of patients in both groups were neurologically intact (342 and 319 in operative and nonoperative groups, respectively). Among the studies that reported the data, the mean LOS was 14 days in the operative group and 20.75 in the nonoperative group.

The incidence of all complications in the operative and nonoperative groups was $300(32.6 \%)$ and 21 (4.8\%), respectively, which was not significant $(\mathrm{p}=0.1065)(\mathrm{Ta}-$ ble 3). There was no significant difference between the 2 groups with respect to the incidence of pulmonary, thromboembolic, cardiac, and gastrointestinal complications. However, the incidence of infection (pneumonia, urinary tract infection, wound infection, and sepsis) was significantly higher in the operative group $(p=0.0009)$. The incidence of instrumentation failure and need for revision surgery was $4.35 \%$ (40 of 919), a significant morbidity, and an event obviously unique to the operative category $(p=0.004)$.

\section{Discussion}

Treatment of lumbar and thoracolumbar traumatic spine fractures carries the potential for significant morbidity no matter which management scheme is used. Both operative and nonoperative modalities have been illustrated to have significant adverse events, and this is despite the relatively young age of patients in the operative and nonoperative groups (43 and 34 years, respectively).

\section{Operative Versus Nonoperative Management of} Thoracolumbar Burst Fractures

Several studies have suggested superiority of either operative or nonoperative management of thoracolumbar fractures. , $15,20,27,35,39,40$ Specifically, 1 retrospective cohort study ${ }^{19}$ comparing operative to nonoperative management concluded that surgery is superior, for its ability to provide an early return to full-time work. However, the lack of high-quality evidence-based literature makes these conclusions uncertain.

Of the approximately 1500 abstracts reviewed, there was only 1 Level I study, a randomized trial by Wood and

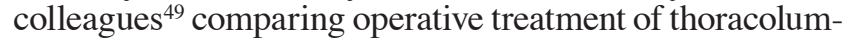
bar burst fractures to bracing in the neurologically intact patient. They found equivalence between the 2 groups with regard to functional outcome. These findings by Wood et al. were corroborated by Abudou and colleagues. ${ }^{1}$ In a Cochrane review of operative versus nonoperative outcomes of burst fractures without neurological deficit, it was concluded that there was inadequate evidence to support the surgical treatment of burst fractures with the goal of limiting pain and improving functional outcome. Shen and colleagues provide further support for Wood's conclusions with equivocal results of a prospective study comparing nonoperative treatment (brace) to short-segment fixation for thoracolumbar junction fractures. ${ }^{40}$ In this study, despite superior kyphosis correction $\left(4^{\circ}\right)$ and earlier pain relief in favor of surgery, no difference in functional outcome was noted at a 2-year follow-up. Bailey and coinvestigators conducted a randomized multicenter study to compare the effects of bracing on functional outcome in thoracolumbar burst fractures (AO Type A3). ${ }^{5}$ In the absence of posterior ligamentous complex disruption on imaging, and obvious comorbidity, the coinvestigators concluded that the inherent stability of burst fractures meant that there was no additional benefit to spinal stability provided by bracing. The aforementioned studies lend further credit to the belief that burst fractures are stable injuries in the absence of posterior ligamentous complex injury. To date, numerous studies report equivalence between surgery and orthosis, or report "good" functional outcomes by orthosis alone for thoraco-

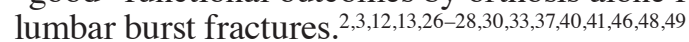

However, contradictory conclusions were later reported. Siebenga and colleagues ${ }^{42}$ followed up prior equivocal studies with a randomized study of thoracolumbar burst fractures (AO Type A3-burst only) in which they compared short-segment fixation to bracing. Thirty-two patients were followed for 4 years ( $92 \%$ follow-up), finding superior functional outcome and pain scores in the surgical group (Roland Morris Disability Questionnaire, visual analog scale [VAS] and VAS spine scores).

\section{Adverse Events in Operative and Nonoperative Burst Fractures}

The primary aim of the present study was to compare adverse events for nonoperative and operative management of traumatic fractures of the thoracolumbar spine as previously reported in the literature. A common misperception is that operative intervention lowers the rate of complications due to early ambulation. In our review of the literature, we found 300 complications in the operative group (32.6\%) versus 21 in the nonoperative group $(4.8 \%)$.

Wood and colleagues ${ }^{49}$ found a higher incidence of complications in the surgical group, despite having no major long-term advantages. A Cochrane review by Abudou et al. ${ }^{1}$ found 2 studies that were eligible for inclu- 
TABLE 1: Results of MEDLINE search—operative and nonoperative manuscripts*

\begin{tabular}{|c|c|c|c|c|}
\hline Authors \& Year & Journal & Study Design & CEBM Grade & No. of Pts \\
\hline \multicolumn{5}{|l|}{ operative group } \\
\hline Pakzad et al., 2011 & Can J Surg & prosp & ॥ & 83 \\
\hline Campbell et al., 2011 & Neurosurg Focus & prosp & $\|$ & 202 \\
\hline Gnanenthiran et al., 2012 & Clin Orthop Relat Res & meta & I & 41 \\
\hline Kerwin et al., 2007 & J Trauma & prosp & II & 361 \\
\hline Pfeifer et al., 2012 & J Trauma Manag Outcomes & prosp & ॥ & 70 \\
\hline Schnee \& Ansell, 1997 & J Neurosurg & retro & III & 25 \\
\hline Wang et al., 2006 & Spine & prosp & II & 58 \\
\hline Stadhouder et al., 2008 & Spine & retro & IV & 114 \\
\hline Haiyun et al., 2010 & Spine & prosp & II & 37 \\
\hline Wei et al., 2010 & Spine & prosp & II & 85 \\
\hline Resnick \& Benzel, 1998 & Neurosurgery & retro & III & 33 \\
\hline Nguyen et al., 2003 & J Spinal Disord Tech & retro & III & 10 \\
\hline Rechtine et al., 1999 & J Spinal Disord & prosp & $\|$ & 117 \\
\hline \multicolumn{5}{|l|}{ nonoperative group } \\
\hline Gnanenthiran et al., 2012 & Clin Orthop Relat Res & meta & I & 38 \\
\hline Chapman et al., 2008 & Spine & post hoc & IV & 151 \\
\hline Stadhouder et al., 2008 & Spine & parallel cohort & $\|$ & 95 \\
\hline Wood et al., 2003 & J Bone Joint Surg Am & $\mathrm{RCT}$ & I & 47 \\
\hline Rechtine et al., 1999 & J Spinal Disord & prosp & II & 118 \\
\hline
\end{tabular}

sion and concluded that there was insufficient evidence in this comparison of operative to nonoperative treatment of burst fractures. Furthermore, complications could not be tracked because the included studies did not track them. Siebenga and colleagues ${ }^{42}$ found a similar complication rate in a multicenter prospective trial randomizing $\mathrm{AO}$ Type A3 thoracolumbar fractures to either operative or nonoperative treatment (29\% vs $20 \%$, or 5 vs 3 complications, respectively). These findings are difficult to interpret in the face of a limited recruitment, with only 34 patients included in the study.

Rechtine and colleagues ${ }^{36}$ reviewed 235 patients with

TABLE 2: Baseline characteristics in 1355 patients with thoracolumbar spine fractures

\begin{tabular}{|c|c|c|c|}
\hline \multirow[b]{2}{*}{ Characteristic } & \multicolumn{2}{|c|}{ Group } & \multirow[b]{2}{*}{$p$ Value } \\
\hline & Op & Nonop & \\
\hline total no. & 919 & 436 & 0.974 \\
\hline no. $(\%)$ female & $316(35)$ & $173(40)$ & 0.404 \\
\hline mean age in yrs (SD) & $43.17(11.1)$ & $34.68(5.5)$ & 0.3865 \\
\hline \multicolumn{4}{|l|}{ Frankel grade* } \\
\hline$A$ & 38 & 29 & NA \\
\hline$B-D$ & 109 & 63 & NA \\
\hline$E$ & 342 & 319 & NA \\
\hline mean LOS in days (SD) & $14.2(5.0)$ & $20.75(17.1)$ & 0.3754 \\
\hline
\end{tabular}

* From studies reporting functional status. NA = not available. thoracolumbar trauma retrospectively, finding no difference in decubitus ulcers, thromboembolism, or mortality. There are many confounders in the population of patients with multiple traumas that are not taken into consideration in the studies we reviewed, which may confer a higher adverse event rate. For example, prior work has shown that mobilization off of a backboard, rather than surgical intervention, may be the most influential factor in preventing decubitus ulcers, ${ }^{14}$ supporting the conclusions of Rechtine et al. In a review of the nonsurgical management of thoracolumbar burst fractures, Shen and Shen ${ }^{41}$ found no cases of decubitus ulcers or thromboembolism

TABLE 3: Operative versus nonoperative complications in 1355 patients with thoracolumbar spine fractures*

\begin{tabular}{lccl}
\hline \multirow{2}{*}{\multicolumn{1}{c}{ Complication }} & \multicolumn{2}{c}{ Group } & \\
\cline { 2 - 3 } & Op & Nonop & p Value \\
\hline pulmonary & 60 & 3 & 0.727 \\
thromboembolic & 20 & 9 & 0.841 \\
infection (PNA, UTI, wound) & 51 & 0 & 0.000875 \\
cardiac & 8 & 0 & 1 \\
gastrointestinal & 5 & 0 & 0.948 \\
revision for instr failure & 40 & 0 & 0.00396 \\
other & 116 & 9 & \\
total no. (\%) & $300(32.6)$ & $21(4.8)$ & 0.1065 \\
\hline
\end{tabular}

* Instr = instrumentation; PNA = pneumonia; UTI = urinary tract infection. 
in patients without neurological deficit. This is surprising in that advocates of surgery argue that surgery lowers complications related to being immobile. However, neurological grade probably plays an even greater role in adverse events, and that warrants further study.

The incidence of surgical site infection in spine surgery at major institutions is approximately 5\%, ranging from $0.7 \%$ to $11.9 \%$. The use of vancomycin in the surgical $^{7}$ bed has been shown to lower the infection rate in several studies: ${ }^{24,31,34,43,44}$ however, those data were not available in any of the reviewed literature. Across the studies reviewed, the obvious difference is the incidence of thoracolumbar wound infections, which was statistically higher for the operative than for the nonoperative group, because the latter did not undergo surgery. The number of nonsurgical infections in the operative group was also higher compared with the nonoperatively treated group. Due to the varied range in complication reporting, the infections were reported in aggregate, rather than individually (pulmonary, urinary, sepsis).

\section{Limitations of the Study}

Given the lack of homogeneity among studies, this review suffers from several limitations. The major limitation of the abundant retrospective studies included in this review is the lack of a uniform patient population. In the operative group nearly two-thirds of the complications are specifically described (Table 3 ). This point is illustrated by Rechtine and colleagues' retrospective study, ${ }^{36}$ in which the patient population had a mix of neurologically intact and incomplete patients, guided by surgeon selection. The selection bias makes interpretation of these data difficult without clearly defined inclusion criteria. It is unknown how many patients were deemed not to be medical candidates and therefore biased the nonsurgical complications. However, the crude complication rate was particularly low in the nonsurgical group (4.8\%).

Due to the lack of agreement on the acceptable approach to the thoracolumbar junction, whether anterior, posterior, or combined, the complications were not stratified across studies in the operative category. Regardless of approach, it is evident that there were more complications in the surgical group, contributing to the $32.6 \%$ crude complication rate. More than one-third of the complications in the operative group were procedure related; namely wound infections and implant failures. Determining approach-related complications in this study was not feasible because of the lack of recorded complications and low patient population.

There was a lack of agreement among studies on the definition of a complication as well as the postoperative time period during which a complication can be considered treatment related. The reported studies were predominantly retrospective, and that type of study has been shown to find lower complication rates than prospective studies, ${ }^{9-11}$ as well as less consistent follow-up.

Variability of the LOS data in both groups illustrates that straightforward comparisons between the groups regarding "nonprocedural" complications is difficult. This variability is probably due to the distribution of the multiple traumas seen.

\section{Conclusions}

Due to the limited number of high-quality studies, conclusions related to complication rates of operative and nonoperative management of thoracolumbar traumatic injuries cannot be definitively made. Further prospective, randomized studies of operative versus nonoperative management of thoracolumbar and lumbar spine trauma, with standardized definitions of complications and matched patient cohorts, will aid in properly defining the risk-benefit ratio of surgery for thoracolumbar spine fractures.

\section{Disclosure}

Dr. Vaccaro is a board member for AOSpine, Innovative Surgical Design, Association of Collaborative Spine Research, and Spinicity. He is a consultant for Stout Medical, Gerson Lehrman Group, Guidepoint Global, Medacorp, Innovative Surgical Design, and Orthobullets. He has received clinical or research support for the study described (includes equipment or material) from Stryker Spine, NuVasive, and Cerapedics. He receives royalties from DePuy, Medtronic, Stryker Spine, Biomet Spine, Globus, Aesculap, and $\mathrm{NuVasive}$. He has direct stock ownership in the following companies: Replication Medica, Globus, K-2 Medical, Paradigm Spine, Stout Medical, Spine Medica, Computational Biodynamics, Progressive Spinal Technologies, Spinology, Small Bone Innovations, Cross Current, Syndicom, In Vivo, Flagship Surgical, Advanced Spinal Intellectual Properties, Cytonics, Bonovo Orthopaedics, Electrocore, Gamma Spine, Location Based Intelligence, FlowPharma, R.S.I., Rothman Institute and Related Properties, Innovative Surgical Design, and Spinicity. Dr. Harrop is a consultant for DePuy Spine, and he serves on advisory boards for Bioventus and Tejin. Dr. Arnold is a consultant for Medtronic Sofamor Danek, Lifespine, Integra Life, SpineWave, Stryker Spine, MIEMS, and AOSpine North America. He has received an honorarium from the University of Missouri, and he owns stock in Z-plasty.

Author contributions to the study and manuscript preparation include the following. Conception and design: Harrop, Ghobrial, Vaccaro. Acquisition of data: Ghobrial, Maulucci, Dalyai. Analysis and interpretation of data: Harrop, Ghobrial, Maulucci, Dalyai, Fehlings. Drafting the article: Harrop, Ghobrial, Maulucci, Dalyai. Critically revising the article: Harrop, Vaccaro. Reviewed submitted version of manuscript: Harrop, Ghobrial, Street, Arnold. Statistical analysis: Maltenfort. Study supervision: Harrop.

\section{References}

1. Abudou M, Chen X, Kong X, Wu T: Surgical versus non-surgical treatment for thoracolumbar burst fractures without neurological deficit. Cochrane Database Syst Rev 6:CD005079, 2013

2. Ağuş H, Kayali C, Arslantaş M: Nonoperative treatment of burst-type thoracolumbar vertebra fractures: clinical and radiological results of 29 patients. Eur Spine J 14:536-540, 2005

3. Aligizakis A, Katonis P, Stergiopoulos K, Galanakis I, Karabekios S, Hadjipavlou A: Functional outcome of burst fractures of the thoracolumbar spine managed non-operatively, with early ambulation, evaluated using the load sharing classification. Acta Orthop Belg 68:279-287, 2002

4. Andreychik DA, Alander DH, Senica KM, Stauffer ES: Burst fractures of the second through fifth lumbar vertebrae. Clinical and radiographic results. J Bone Joint Surg Am 78:11561166, 1996

5. Bailey CS, Dvorak MF, Thomas KC, Boyd MC, Paquett S, Kwon $\mathrm{BK}$, et al: Comparison of thoracolumbosacral orthosis and no orthosis for the treatment of thoracolumbar burst fractures: interim analysis of a multicenter randomized clinical equivalence trial. Clinical article. J Neurosurg Spine 11:295-303, 2009 
6. Bedbrook GM: Treatment of thoracolumbar dislocation and fractures with paraplegia. Clin Orthop Relat Res (112):2743, 1975

7. Beiner JM, Grauer J, Kwon BK, Vaccaro AR: Postoperative wound infections of the spine. Neurosurg Focus 15(3):E14, 2003

8. Burke DC, Murray DD: The management of thoracic and thoraco-lumbar injuries of the spine with neurological involvement. J Bone Joint Surg Br 58:72-78, 1976

9. Campbell PG, Malone J, Yadla S, Maltenfort MG, Harrop JS, Sharan AD, et al: Early complications related to approach in thoracic and lumbar spine surgery: a single center prospective study. World Neurosurg 73:395-401, 2010

10. Campbell PG, Yadla S, Malone J, Maltenfort MG, Harrop JS, Sharan AD, et al: Complications related to instrumentation in spine surgery: a prospective analysis. Neurosurg Focus 31(4): E10, 2011

11. Campbell PG, Yadla S, Malone J, Zussman B, Maltenfort MG, Sharan AD, et al: Early complications related to approach in cervical spine surgery: single-center prospective study. World Neurosurg 74:363-368, 2010

12. Cantor JB, Lebwohl NH, Garvey T, Eismont FJ: Nonoperative management of stable thoracolumbar burst fractures with early ambulation and bracing. Spine (Phila Pa 1976) 18:971976, 1993

13. Chan DP, Seng NK, Kaan KT: Nonoperative treatment in burst fractures of the lumbar spine (L2-L5) without neurologic deficits. Spine (Phila Pa 1976) 18:320-325, 1993

14. Curry K, Casady L: The relationship between extended periods of immobility and decubitus ulcer formation in the acutely spinal cord-injured individual. J Neurosci Nurs 24:185-189, 1992

15. Dai LY: Remodeling of the spinal canal after thoracolumbar burst fractures. Clin Orthop Relat Res (382):119-123, 2001

16. Dai LY, Jiang SD, Wang XY, Jiang LS: A review of the management of thoracolumbar burst fractures. Surg Neurol 67: 221-231, 2007

17. Davies WE, Morris JH, Hill V: An analysis of conservative (non-surgical) management of thoracolumbar fractures and fracture-dislocations with neural damage. J Bone Joint Surg Am 62:1324-1328, 1980

18. Denis F: The three column spine and its significance in the classification of acute thoracolumbar spinal injuries. Spine (Phila Pa 1976) 8:817-831, 1983

19. Denis F, Armstrong GW, Searls K, Matta L: Acute thoracolumbar burst fractures in the absence of neurologic deficit. A comparison between operative and nonoperative treatment. Clin Orthop Relat Res (189):142-149, 1984

20. El-Awad AA, Othman W, Al-Moutaery KR: Treatment of thoracolumbar fractures. Saudi Med J 23:689-694, 2002

21. Esses SI, Botsford DJ, Kostuik JP: Evaluation of surgical treatment for burst fractures. Spine (Phila Pa 1976) 15:667-673, 1990

22. Fehlings MG, Vaccaro A, Wilson JR, Singh A, Cadotte DW, Harrop JS, et al: Early versus delayed decompression for traumatic cervical spinal cord injury: results of the Surgical Timing in Acute Spinal Cord Injury Study (STASCIS). PLoS ONE 7:e32037, 2012

23. Frankel HL, Hancock DO, Hyslop G, Melzak J, Michaelis LS, Ungar GH, et al: The value of postural reduction in the initial management of closed injuries of the spine with paraplegia and tetraplegia. Paraplegia 7:179-192, 1969

24. Godil SS, Parker SL, O'Neill KR, Devin CJ, McGirt MJ: Comparative effectiveness and cost-benefit analysis of local application of vancomycin powder in posterior spinal fusion for spine trauma. Clinical article. J Neurosurg Spine 19:331335,2013

25. Heneghan C: EBM resources on the new CEBM website. Evid Based Med 14:67, 2009
26. Knight RQ, Stornelli DP, Chan DP, Devanny JR, Jackson KV: Comparison of operative versus nonoperative treatment of lumbar burst fractures. Clin Orthop Relat Res (293):112121,1993

27. Kraemer WJ, Schemitsch EH, Lever J, McBroom RJ, McKee MD, Waddell JP: Functional outcome of thoracolumbar burst fractures without neurological deficit. J Orthop Trauma 10: 541-544, 1996

28. Krompinger WJ, Fredrickson BE, Mino DE, Yuan HA: Conservative treatment of fractures of the thoracic and lumbar spine. Orthop Clin North Am 17:161-170, 1986

29. Limb D, Shaw DL, Dickson RA: Neurological injury in thoracolumbar burst fractures. J Bone Joint Surg Br 77:774-777, 1995

30. McEvoy RD, Bradford DS: The management of burst fractures of the thoracic and lumbar spine. Experience in 53 patients. Spine (Phila Pa 1976) 10:631-637, 1985

31. Molinari RW, Khera OA, Molinari WJ III: Prophylactic intraoperative powdered vancomycin and postoperative deep spinal wound infection: 1,512 consecutive surgical cases over a 6-year period. Eur Spine J 21 (Suppl 4):S476-S482, 2012

32. Müller U, Berlemann U, Sledge J, Schwarzenbach O: Treatment of thoracolumbar burst fractures without neurologic deficit by indirect reduction and posterior instrumentation: bisegmental stabilization with monosegmental fusion. Eur Spine J 8:284-289, 1999

33. Mumford J, Weinstein JN, Spratt KF, Goel VK: Thoracolumbar burst fractures. The clinical efficacy and outcome of nonoperative management. Spine (Phila Pa 1976) 18:955-970, 1993

34. O'Neill KR, Smith JG, Abtahi AM, Archer KR, Spengler DM, McGirt MJ, et al: Reduced surgical site infections in patients undergoing posterior spinal stabilization of traumatic injuries using vancomycin powder. Spine J 11:641-646, 2011

35. Ramieri A, Domenicucci M, Passacantilli E, Nocente M, Ciappetta P: The results of the surgical and conservative treatment of non-neurologic comminuted thoracolumbar fractures. Chir Organi Mov 85:129-135, 2000

36. Rechtine GR II, Cahill D, Chrin AM: Treatment of thoracolumbar trauma: comparison of complications of operative versus nonoperative treatment. J Spinal Disord 12:406-409, 1999

37. Reid DC, Hu R, Davis LA, Saboe LA: The nonoperative treatment of burst fractures of the thoracolumbar junction. J Trauma 28:1188-1194, 1988

38. Rihn JA, Anderson DT, Harris E, Lawrence J, Jonsson H, Wilsey J, et al: A review of the TLICS system: a novel, userfriendly thoracolumbar trauma classification system. Acta Orthop 79:461-466, 2008

39. Seybold EA, Sweeney CA, Fredrickson BE, Warhold LG, Bernini PM: Functional outcome of low lumbar burst fractures. A multicenter review of operative and nonoperative treatment of L3-L5. Spine (Phila Pa 1976) 24:2154-2161, 1999

40. Shen WJ, Liu TJ, Shen YS: Nonoperative treatment versus posterior fixation for thoracolumbar junction burst fractures without neurologic deficit. Spine (Phila Pa 1976) 26:10381045, 2001

41. Shen WJ, Shen YS: Nonsurgical treatment of three-column thoracolumbar junction burst fractures without neurologic deficit. Spine (Phila Pa 1976) 24:412-415, 1999

42. Siebenga J, Leferink VJ, Segers MJ, Elzinga MJ, Bakker FC, Haarman HJ, et al: Treatment of traumatic thoracolumbar spine fractures: a multicenter prospective randomized study of operative versus nonsurgical treatment. Spine (Phila Pa 1976) 31:2881-2890, 2006

43. Strom RG, Pacione D, Kalhorn SP, Frempong-Boadu AK: Decreased risk of wound infection after posterior cervical fusion with routine local application of vancomycin powder. Spine (Phila Pa 1976) [epub ahead of print], 2013

44. Strom RG, Pacione D, Kalhorn SP, Frempong-Boadu AK: Lumbar laminectomy and fusion with routine local applica- 


\section{Review of adverse events in managing thoracolumbar fractures}

tion of vancomycin powder: decreased infection rate in instrumented and non-instrumented cases. Clin Neurol Neurosurg 115:1766-1769, 2013

45. Thomas KC, Bailey CS, Dvorak MF, Kwon B, Fisher C: Comparison of operative and nonoperative treatment for thoracolumbar burst fractures in patients without neurological deficit: a systematic review. J Neurosurg Spine 4:351-358, 2006

46. Tropiano P, Huang RC, Louis CA, Poitout DG, Louis RP: Functional and radiographic outcome of thoracolumbar and lumbar burst fractures managed by closed orthopaedic reduction and casting. Spine (Phila Pa 1976) 28:2459-2465, 2003

47. van der Roer N, de Lange ES, Bakker FC, de Vet HC, van Tulder MW: Management of traumatic thoracolumbar fractures: a systematic review of the literature. Eur Spine J 14:527-534, 2005

48. Weinstein JN, Collalto P, Lehmann TR: Thoracolumbar "burst" fractures treated conservatively: a long-term follow-up. Spine (Phila Pa 1976) 13:33-38, 1988
49. Wood K, Buttermann G, Mehbod A, Garvey T, Jhanjee R, Sechriest V: Operative compared with nonoperative treatment of a thoracolumbar burst fracture without neurological deficit. A prospective, randomized study. J Bone Joint Surg Am 85-A:773-781, 2003 (Erratum in J Bone Joint Surg Am 86A:1283, 2004)

Manuscript submitted February 27, 2014.

Accepted April 3, 2014.

Please include this information when citing this paper: DOI: 10.3171/2014.4.FOCUS1467.

Address correspondence to: James S. Harrop, M.D., Department of Neurological Surgery, Thomas Jefferson University Hospital, 909 Walnut St., 3rd Floor, Philadelphia, PA 19107. email: james. harrop@jefferson.edu. 